\title{
Benign tumors of the orbit in children and adolescents - clinical and histopathological analysis
}

\author{
Marta Świerczyńska ${ }^{1,2}$, Erita Filipek ${ }^{1,2}$ \\ 'Department of Pediatric Ophthalmology, Faculty of Medical Sciences in Katowice, Medical University of Silesia, Katowice, Poland \\ ${ }^{2}$ Department of Pediatric Ophthalmology, Kornel Gibiński University Clinical Center, Medical University of Silesia, Katowice, Poland
}

\begin{abstract}
Aim: The aim of the study was to conduct a retrospective histopathological and clinical analysis of benign tumors of the orbit in children and adolescents treated in the Clinic of Pediatric Ophthalmology of the Medical University of Silesia in Katowice. Material and methods: The study included 1344 patients, who underwent surgical removal of nodular lesions in the Department of Pediatric Ophthalmology of the Medical University of Silesia in Katowice between 2010 and 2020. Tumors of the orbit constituted $23.7 \%$ (172 patients). The excised lesions underwent histopathological examination. The study group consisted of 97 girls (56.4\%) and 75 boys (43.6\%) aged from 6 months to 17 years. The average age was $3.7 \pm 4.9$ years. The patients were divided into four age groups: 0-4 years, 5-9 years, 10-14 years, $15-18$ years.
\end{abstract}

Results: In the above age groups, orbital tumors occurred in $71.5 \%$, $13.4 \%, 9.3 \%$, and $5.8 \%$, respectively. Histopathology results most often showed: dermoid cysts (47.1\%) epidermal cysts (21.5\%) and dermolipomas (18\%). The majority of dermoids arise in the upper temporal region from the frontozygomatic suture. All patients underwent surgical excisions of lesions because of unpredictable progression and possible complications. Eligibility for resection of dermolipomas or lipomas depended on tumor size, concomitant symptoms and cosmetic aspects.

Conclusions: According to our data, the most common benign tumors in children and adolescents were dermoid and epidermal cysts. Choristomas have typical locations and clinical picture. Treatment of these lesions involves a surgical excision, and subsequent histopathological evaluation is always required.

KEY WORDS: benign tumors, orbit, histopathological diagnosis, clinical picture, children.

\section{INTRODUCTION}

Benign orbital tumors in children and adolescents are found more often than in adults. They are characterized by a different clinical picture, location and dynamics of development [1-5]. These lesions can be primary, secondary or metastatic [6-8].

Depending on the size and location, tumors may remain asymptomatic or distort the outline of the orbit and as they grow cause subsequent deformation and bone erosion, eyeball displacement and ocular motility disturbance, pressure on the extraocular muscles, double vision, decreased visual acuity, amblyopia, secretory function of the lacrimal gland disturbance, deformation of the shape of the eyelids and their drooping. Lesions in contact with the optic nerve induce symptoms related to its compression. Moreover, a cyst may rupture and cause local inflammation as a result of an injury or spontaneously $[2,4,7,9-12]$. Imaging tests are es- pecially important in the diagnosis of orbital neoplasms, and removed lesions should be subject to histopathological evaluation $[4,7,10,11]$.

In terms of pathomorphology, non-malignant neoplasms can be divided into: choristomas (growth of normal tissue growing in an inappropriate place, a form of heterotopia; includes dermoid and epidermal cysts), hamartomas (excessive growth of tissue in its anatomical place, e.g. hemangiomas) and pseudotumors (inflammatory and other) $[10,11]$. Katowitz et al. [10] published a summary of studies on lesions in developmental age diagnosed as benign orbital tumors. Almost 2,000 analyzed cases show a wide spectrum of diagnoses. The most numerous group included inflammatory, infectious and non-infectious (abscesses and tissue inflammations) disorders. In addition, the following were distinguished: cystic tumors, neurogenic, vascular, bony, histiocytic, and degenerative lesions, as well as those related to injuries. 


\section{AIM OF THE STUDY}

The aim of the study was a retrospective clinical and histopathological evaluation of benign tumors of the orbit in children and adolescents undergoing surgical treatment based on material of the Clinic of Pediatric Ophthalmology of the Medical University of Silesia in Katowice.

\section{MATERIAL AND METHODS}

The analysis included 172 patients, 97 girls (56.4\%) and 75 boys (43.6\%), aged 6 months to 17 years (mean age $3.7 \pm 4.9$ years), operated in the clinic in 2010-20120 due to the presence of benign orbital tumors. The subjects were divided into 4 age groups: 0-4 years, 5-9 years, $10-14$ years and $15-18$ years. The removed lesions were submitted to histopathological verification. Tumor-like lesions were excluded from the analysis.

\section{RESULTS}

From October 2010 to August 2020, in the clinic, ocular tumors were removed in 1344 patients aged 6 months to 18 years (mean age $7.6 \pm 5.9$ years). Benign neoplasms accounted for $54.1 \%$ of diagnoses, and nodular inflammatory processes dominated among the remaining lesions. Tumors were most often located in the conjunctiva $(34.1 \%)$, on the eyelids $(24.7 \%)$, in the orbit $(23.7 \%)$ and less frequently in the corneal limbus $(9.5 \%)$, the lacrimal caruncle (5.9\%) and the plica semilunaris $(2.1 \%)$.

Benign neoplasms of the orbit were removed in $172 \mathrm{pa}-$ tients. In the age groups 0-4 years, 5-9 years, 10-14 years, $15-18$ years, the above-mentioned lesions occurred in $71.5 \%$, $13.4 \%, 9.3 \%$, and $5.8 \%$ of patients, respectively. Single, unilateral tumors dominated. Only two children had coexistence of a dermoid cyst and an orbital lipoma. The results of histopathological examinations showed that in the treated patients the most common were dermoid and epidermal cysts as well as dermolipomas, classified as choristomas (Table I).

Children were qualified for surgery because of the gradual enlargement of nodular lesions within the orbital tissues, as well as epibulbar lesions that penetrated deep into them. In older patients, cosmetic reasons prevailed. In most cases, pathological symptoms were observed from the day of birth. However, sometimes parents noticed the lesion later, when the amount of periorbital fat began to decrease as the child grew, allowing better visualization of the tumor. The lesions were also detected accidentally during palpation, e.g. while washing the face of a child.

All patients underwent a complete ophthalmological examination, supplemented by an ultrasound examination of the eyes. In selected cases, computed tomography (CT) was performed to assess whether the tumor models the orbital bone or the eyeball. No reduction in visual acuity or abnormalities in the anterior and posterior segments of the eye were found among the examined persons.

\section{DISCUSSION}

Among the operated patients, dermoid and epidermal cysts accounted for $68.6 \%$ of all excised tumors. According to the literature data $[1,3,4,7,9,10,13-15]$, dermoids are the most common benign lesions within the eyelids, corneal limbus and orbit, which is consistent with the results of our current and previous observations [5]. In terms of pathomorphology, there are 4 types of choristomas: dermoid, dermolipoma, single-tissue choristoma and complex choristoma. Dermoid cysts are the most common among dermoid tumors. To confirm their presence, it is necessary to find elements of the skin adnexa, especially the lacrimal glands. In contrast, epidermal cysts lack these adnexa $[4,8,10]$.

Dermoid cysts are formed between the 3rd and 5th week of fetal life as a result of the sequestration of the ectoderm and/or mesoderm from the surface of the embryo and its movement under the skin through the fetal closure lines of the bones. This explains their typical location, most often in the upper temporal part of the orbit, in conjunction with the frontozygomatic suture (60-86\%) or, much less often, in the upper nasal part of the orbit, in conjunction with the frontonasal suture (10\% to $25 \%)[3,4,8-10,12,13,16,17]$.

Dermoid cysts are divided into superficial and deep [18]. The former are more frequent and usually appear up to the age of 3 . They are usually smooth, hard, removable and painless nodules in the subcutaneous tissue, near the brow bone, and the skin above them remains unchanged (Fig. 1, 2). They are characterized by slow growth and usually do not cause functional disturbances. [3, 8, 9, 11, 12, 15, 17]. Deep dermoid cysts, on the other hand, often remain undetected for many years, and their first symptom may be exophthalmos or deformation of the orbit. They require detailed imaging diagnostics in order to precisely plan the surgery $[7,9,10,13]$.

Table I. Histopathological and clinical characteristics of benign tumors of the orbit in children and adolescents.

\begin{tabular}{|c|c|c|c|c|c|c|}
\hline \multirow{2}{*}{ Histopathological diagnosis } & \multirow{2}{*}{$\begin{array}{l}\text { Number of children } \\
\qquad(n=172)\end{array}$} & \multirow{2}{*}{$\begin{array}{l}\text { Gender } \\
\text { Girls : Boys }\end{array}$} & \multicolumn{4}{|c|}{ Age (years) } \\
\hline & & & $0-4$ & $5-9$ & $10-14$ & $15-18$ \\
\hline Cystis dermoidalis & 81 & $44: 37$ & 65 & 9 & 4 & 3 \\
\hline Cystis epidermalis & 37 & $19: 18$ & 27 & 7 & 2 & 1 \\
\hline Dermolipoma & 31 & $18: 13$ & 17 & 6 & 5 & 3 \\
\hline Lipoma & 19 & $13: 6$ & 13 & 1 & 3 & 2 \\
\hline Fibrolipoma & 3 & $2: 1$ & - & - & 2 & 1 \\
\hline Teratoma & 1 & $1: 0$ & 1 & - & - & - \\
\hline
\end{tabular}



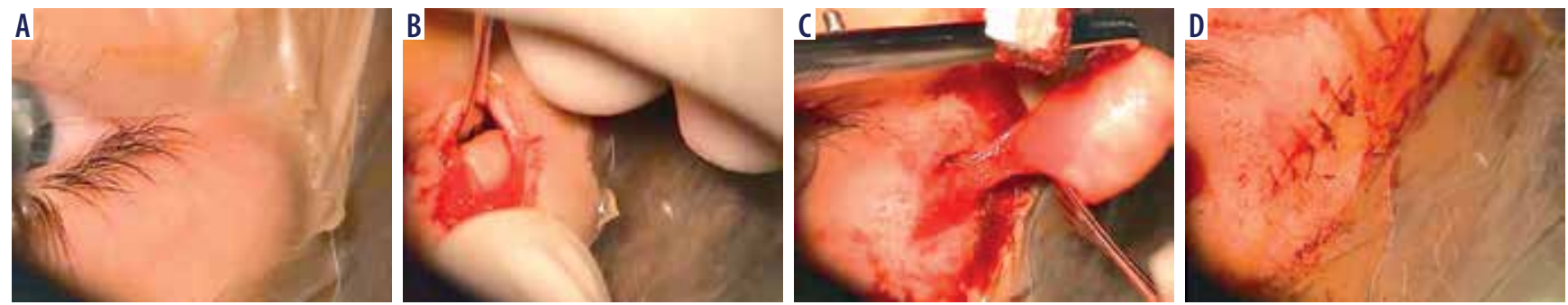

Figure 1. Dermoid cyst of the orbit
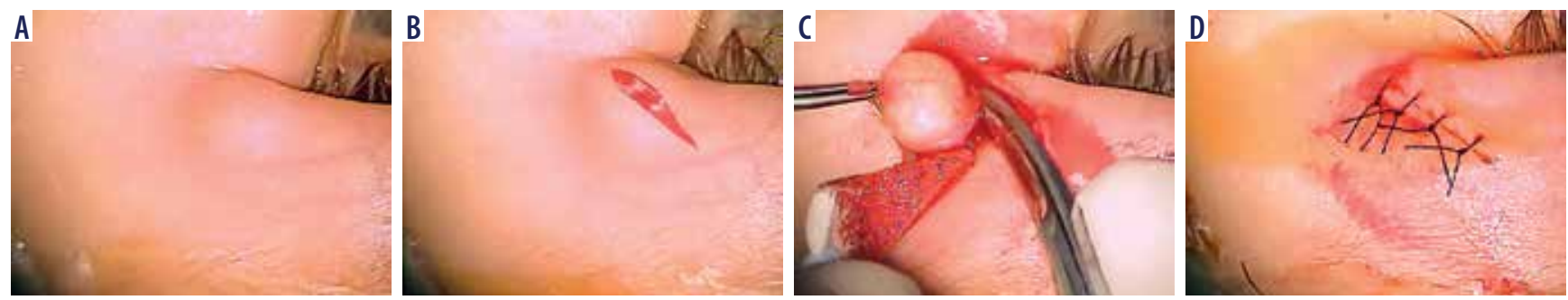

Figure 2. Dermoid cyst of the orbit
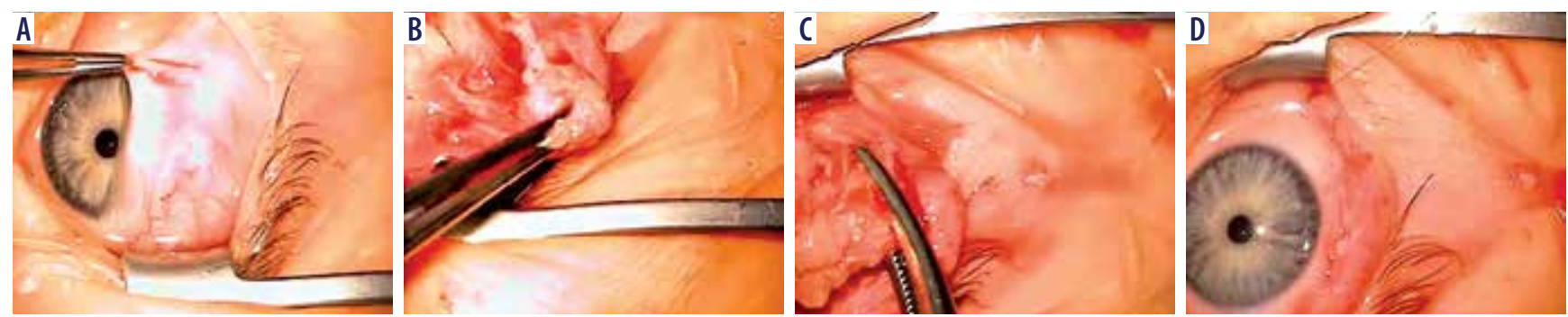

Figure 3. Epibulbar dermolipoma

Progression of dermoid cysts can be difficult to determine. In the group we analyzed, children were qualified for surgery taking into account presumable complications, including the possibility of a cyst rupture. In some of the operated patients, especially the older ones, fusion of the tumor with the orbital periosteum was found, as well as bone deformities [3, 9, 10, $12,13,15-17,19]$. As dermoids grow their wall becomes thinner and the contents of the cyst (mainly lipids and keratin) leak. As a consequence, chronic inflammation and fibrosis begin in adjacent tissues. It is postulated that more than $2 / 3$ of the excised cysts show different degrees of progression of the inflammatory process in histopathological examination. Additionally, the risk of developing inflammatory lesions increases with age $[10,12,16]$. It is worth mentioning that after early excision of tumors, no eyelid or eye dysfunctions were observed among the treated patients and the cosmetic effects were satisfactory.

Teratomas, which contain elements from all three germ cell layers, are another rare type of tumors. They probably arise from a primitive pluripotent germ cell, which then differentiates into mature structures. An orbital teratoma can be cystic or solid and causes exophthalmos, which is usually visible at birth and may gradually increase. Vision loss occurs as a result of chronically increased intraocular pressure, optic nerve atrophy and keratopathy $[8,11]$. In CT, teratoma appears as a multi-chambered lesion that may be accompanied by orbital enlargement and intracranial hyperplasia $[8,10]$. In such cases, tumor resection is performed in cooperation with neurosurgeons. Complete teratoma removal is mandatory because of possible presence of malignant features in the above tumors and the reports of malignant transformation in an incompletely excised lesion $[20,21]$. When vision is present in the affected globe, attempts can be made to separate the tumor from the globe and optic nerve during orbitotomy. However, limited exenteration of the globe and teratoma is undertaken in patients without identifiable visual function and a deformed globe. In such cases, the mentioned procedure aims to preserve uninvolved orbital structures [10]. There was one teratoma among the patients we examined; fortunately its small size allowed for surgical removal without damaging the eyeball.

Epibulbar-orbital dermolipomas and lipomas were the most extensive benign tumors in the analyzed group. They appeared as soft, removable, pale pink or yellow-pink lesions 
with non-cystic lobular structure, and their surface was often keratinous (Fig. 3). These lesions typically fill the temporal parts of the conjunctival fornices, most often the superior ones. Then they cross the orbital septum and drill into the orbit, in the vicinity of the lateral rectus muscle or the lacrimal gland. Occasionally they induce pressure on the eyeball, develop astigmatism and also cause the dry eye syndrome or strabismus $[3,4,10,15]$. Dermolipomas are seen more frequently in congenital developmental disorders, mainly involving the craniofacial complex: Goldenhar syndrome, Treacher Collins syndrome, linear nevus sebaceous syndrome, hemifacial microsomia and facial cleft [10, 22-26]. In the case of surgical treatment of non-cystic nodular lesions, without clearly defined boundaries, there is no unequivocal opinion about the need for their early removal. Such an indication exists when the mobility of the eyeball is impaired or there is visual dysfunction. In the case of asymptomatic lesions, the decisive factors are the tumor size and cosmetic considerations. The extent of the surgery is usually limited to excision of the anterior part of the lesion. The close proximity of the lacrimal ductules, the palpebral lobe of the lacrimal gland, the lateral rectus muscle as well as the lateral horn of the levator palpebrae superioris may complicate complete resection $[4,10]$. No regrowth of the incompletely removed epibulbar lesions was found in the studied group.

Surgical treatment of the above-mentioned tumors was performed under general anesthesia. Depending on the location, the lesion was removed from the anterior orbital access or from a cutaneous or conjunctival incision. Skin incisions were made directly above the tumor (along the line of Langer) and in the case of lesions in the brow bone area, below the brow hairs. The encysted tumors were completely removed, except for 4 whose walls ruptured during isolation (their sacs were later completely excised). During the surgery, it was possible to say that some of the lesions fused with the periosteum of the orbit, creating cavities. Their walls were separated from the periosteum without damaging the deeper bone structures. When the lesion located in the superior temporal part of the orbit was removed, attention was paid to the vicinity of the lacrimal gland and its protection against damage.

Epibulbar tumors irregularly shaped and occupying the retrobulbar space were excised within the available visual limits. Oculomotor muscles in the operative field were extracted from the surrounding tumor tissue and visualized to prevent their accidental cutting. The operations were uneventful and the wounds healed without complications, leaving smooth, linear, non-discolored scars.

\section{CONCLUSIONS}

The spectrum of benign ocular tumors in developmental age is wide, and the orbit remains one of the most comon location of these lesions. The most frequently diagnosed tumors are choristomas, which have typical locations and a characteristic clinical picture. Treatment of these neoplasms involves their excision with subsequent histopathological evaluation. However, the strategy of surgical treatment depends on the location and extent of the lesion and accompanying symptoms.

\section{DISCLOSURE}

The authors declare no conflict of interest.

\section{References}

1. Domingo RED, Manganip LE, Castro RM. Tumors of the eye and ocular adnexa at the Philippine Eye Research Institute: a 10-year review. Clin Ophthalmol 2015; 9: 1239-1247.

2. Alkatan HM, Marek FA, Elkhamary S. Demographics of pediatric orbital lesions: a tertiary eye center experience in Saudi Arabia. J Epidemiol Glob Health 2019; 9: 3-10.

3. Niwald A, Orawiec B, Grałek M. Nowotwory łagodne narządu wzroku u dzieci - obserwacje własne. Okulistyka 2006; 4: 19-22.

4. Niwald A, Grałek M, Orawiec B, et al. Łagodne guzy oczodołu u dzieci - obserwacje własne. Okulistyka 2012; 1: 7-9.

5. Świerczyńska M, Tobiczyk E, Argier N, et al. Łagodne guzy narządu wzroku u dzieci i młodzieży - analiza materiału klinicznego. Okulistyka 2018; 3: 97-100.

6. Gupta N, Kaur J, Rajwanshi A, et al. Spectrum of orbital and ocular adnexal lesions: an analysis of 389 cases diagnosed by fine needle aspiration cytology. Diagn Cytopathol 2012; 40: 582-585.

7. Rodrigues MC, Tostes VS, Caran EM, et al. Differential diagnosis of orbital tumors in children. Int J Radiol Radiat Ther 2017; 3: 252256.

8. Shields JA, Shields CL. Orbital cysts of childhood - classification, clinical features and management. Surv Ophthalmol 2004; 4: 281-299.

9. Ahuja R, Azar NF. Orbital dermoids in children. Semin Ophthalmol 2006; 21:207-211.

10. Katowitz WR, Fries PD, Kazim M. Benign pediatric orbital tumors. In: Katowitz JA, Katowitz WR (ed.). Pediatric Oculoplastic Surgery. 2nd ed. Springer International Publishing AG 2018; 667-742.

11. Gralek M, Niwald A, Wiśniewska-Krawczyk E. Łagodne guzy narządu wzroku u dzieci i młodzieży. Przegl. Pediatr. 2001; 31: 112-114.

12. Bajric J, Gripentrog J, Mohney BG. Pediatric periocular dermoid cysts: incidence, clinical characteristics and surgical outcomes 2018. Ophthalmic Epidemiol 2019; 26: 117-120.

13. Sadeghi Y, Oberic A, Hamedani M. Different locations of dermoid cysts in the orbital region. Klin Monbl Augenheilkd 2015; 232: 489-492.

14. Kalita LK, Siddique MA, Sarma UCh. Benign eyelids, conjuctival, intraocular and orbital tumors in children: epidemilogy and review of literature. Sch J App Med Sci 2016; 4: 509-516.

15. Niwald A, Orawiec B, Grałek M. Choristoma narządu wzroku u dzieci. Klin Oczna 2007; 109: 297-300.

16. Abou-Rayyah Y, Rose GE, Konrad H, et al. Clinical, radiological and pathological examination of periocular dermoid cysts: evidence of inflammation from an early age. Eye 2002; 16: 507-512. 
17. Lenci LT, Shams P, Shriver E. Dermoid cysts: clinical predictors of complex lesions and surgical complications. J AAPOS 2017; 21: 44-47.

18. Grove AS Jr. Orbital disorders: diagnosis and management. In: McCord Jr CD, editor. Oculoplastic surgery. Raven, New York 1981; 274.

19. Yan J, Zhou S, Li Y. Benign orbital tumors with bone destruction in children. PLoS One. 2012; 7: e32111.

20. Prakash MV, Indira R, Radhakrishnan M, et al. Malignant orbital teratoma in a neonate: A clinicopathological case report. J Postgrad Med 2017; 63: 203-205.

21. Mahesh L, Krishnakumar S, Subramanian N, et al. Malignant teratoma of the orbit: a clinicopathological study of a case. Orbit 2003; 22: 305-309.

22. Fries PD, Katowitz JA. Congenital craniofacial anomalies of ophthalmic importance. Surv Ophthalmol 1990; 35: 87-119.

23. Khong JJ, Hardy TG, McNab AA. Prevalence of Oculo-auriculo-vertebral Spectrum in Dermolipoma. Ophthalmology 2013; 120: 15291532.

24. Kausar A, Zafar SN, Altaf S, Khan A. Ophthalmic manifestations of linear nevus sebaceous/organoid nevus syndrome. J Coll Physicians Surg Pak 2015; 25: 220-222.

25. Spano A, Piozzi E, Cavallini M, et al. Surgical approach in a rare case of coloboma-choristoma. Br J Plast Surg 2005; 58: $732-735$.

26. Lessa S, Sebastiá R, Pontello J. Lateral Canthal Clefts of the Eyelid. Ophthalmic Plast Reconstr Surg 2019; 35: 491-494. 